\title{
Comparative genomics of citric-acid-producing Aspergillus niger ATCC 1015 versus enzyme-producing CBS 513.88
}

Mikael R. Andersen, ${ }^{1}$ Margarita P. Salazar, ${ }^{1,19}$ Peter J. Schaap, ${ }^{2}$ Peter J.I. van de Vondervoort, ${ }^{3}$ David Culley, ${ }^{4}$ Jette Thykaer, ${ }^{1}$ Jens C. Frisvad, ${ }^{1}$ Kristian F. Nielsen, ${ }^{1}$ Richard Albang, ${ }^{5}$ Kaj Albermann, ${ }^{5}$ Randy M. Berka, ${ }^{6}$ Gerhard H. Braus, ${ }^{7}$ Susanna A. Braus-Stromeyer, ${ }^{7}$ Luis M. Corrochano, ${ }^{8}$ Ziyu Dai, ${ }^{4}$ Piet W.M. van Dijck, ${ }^{9}$ Gerald Hofmann, ${ }^{10}$ Linda L. Lasure, ${ }^{4}$ Jon K. Magnuson, ${ }^{4}$ Hildegard Menke, ${ }^{3}$ Martin Meijer, ${ }^{11}$ Susan L. Meijer, ${ }^{1}$ Jakob B. Nielsen, ${ }^{1}$ Michael L. Nielsen, ${ }^{1}$ Albert J.J. van Ooyen, ${ }^{3}$ Herman J. Pel, ${ }^{3}$ Lars Poulsen, ${ }^{1}$ Rob A. Samson, ${ }^{11}$ Hein Stam, ${ }^{3}$ Adrian Tsang, ${ }^{12}$ Johannes M. van den Brink, ${ }^{13}$ Alex Atkins, ${ }^{14}$ Andrea Aerts, ${ }^{14}$ Harris Shapiro, ${ }^{14}$ Jasmyn Pangilinan, ${ }^{14}$ Asaf Salamov, ${ }^{14}$ Yigong Lou, ${ }^{14}$ Erika Lindquist, ${ }^{14}$ Susan Lucas, ${ }^{14}$ Jane Grimwood, ${ }^{15}$ Igor V. Grigoriev, ${ }^{14}$ Christian P. Kubicek, ${ }^{16}$ Diego Martinez, ${ }^{17,18}$ Noël N.M.E. van Peij, ${ }^{3}$ Johannes A. Roubos, ${ }^{3}$ Jens Nielsen, ${ }^{1,19}$ and Scott E. Baker ${ }^{4,20}$

${ }^{1-18}$ [Author affiliations appear at the end of the paper.]

\begin{abstract}
The filamentous fungus Aspergillus niger exhibits great diversity in its phenotype. It is found globally, both as marine and terrestrial strains, produces both organic acids and hydrolytic enzymes in high amounts, and some isolates exhibit pathogenicity. Although the genome of an industrial enzyme-producing A. niger strain (CBS 513.88) has already been sequenced, the versatility and diversity of this species compel additional exploration. We therefore undertook wholegenome sequencing of the acidogenic $A$. niger wild-type strain (ATCC 1015) and produced a genome sequence of very high quality. Only 15 gaps are present in the sequence, and half the telomeric regions have been elucidated. Moreover, sequence information from ATCC 1015 was used to improve the genome sequence of CBS 513.88. Chromosome-level comparisons uncovered several genome rearrangements, deletions, a clear case of strain-specific horizontal gene transfer, and identification of $0.8 \mathrm{Mb}$ of novel sequence. Single nucleotide polymorphisms per kilobase (SNPs/kb) between the two strains were found to be exceptionally high (average: 7.8, maximum: $160 \mathrm{SNPs} / \mathrm{kb}$ ). High variation within the species was confirmed with exo-metabolite profiling and phylogenetics. Detailed lists of alleles were generated, and genotypic differences were observed to accumulate in metabolic pathways essential to acid production and protein synthesis. A transcriptome analysis supported up-regulation of genes associated with biosynthesis of amino acids that are abundant in glucoamylase A, tRNA-synthases, and protein transporters in the protein producing CBS 513.88 strain. Our results and data sets from this integrative systems biology analysis resulted in a snapshot of fungal evolution and will support further optimization of cell factories based on filamentous fungi.

[Supplemental material is available for this article. The A. niger ATCC 1015 whole genome sequence has been submitted to GenBank (http://www.ncbi.nlm.nih.gov/genbank/) under accession no. AC]E00000000. The sequence data from the phylogeny study have been submitted to GenBank under accession nos. GU296686-GU296739. The microarray data from this study have been submitted to the NCBI Gene Expression Omnibus (GEO) (http://www.ncbi.nlm.nih.gov/geo/) under series accession no. GSE10983. The dsmM_ANIGERa_coll511030F library and platform information have been submitted to GEO under accession no. GPL6758.]
\end{abstract}

\footnotetext{
${ }^{19}$ Present address: Systems Biology, Department of Chemical and Biological Engineering, Chalmers University of Technology, SE-41296 Göteborg, Sweden.

${ }^{20}$ Corresponding author.

E-mail scott.baker@pnl.gov; fax (509) 372-4732.

Article published online before print. Article, supplemental material, and publication date are at http://www.genome.org/cgi/doi/10.1101/gr.112169.110. Freely available online through the Genome Research Open Access option.
}

The saprotrophic filamentous fungus Aspergillus niger is found globally and exhibits a great diversity in its phenotype. A. niger has become one of the major workhorses in industrial biotechnology, being very efficient in producing both polysaccharide-degrading enzymes (particularly amylases, pectinases, and xylanases) or organic acids (mainly citric acid) in high amounts. It also has a long history of safe use (Schuster et al. 2002; van Dijck et al. 2003; van 
Dijck 2008). Commercial importance is illustrated by a world market for industrial enzymes of nearly US\$ 5 billion in 2009, of which filamentous fungi account for roughly half of the production (Lubertozzi and Keasling 2008), and a global citric acid production of $9 \times 10^{6}$ metric tons in 2000 (Karaffa and Kubicek 2003).

In 2007, the genome sequence of $A$. niger strain CBS 513.88, used for industrial enzyme production, was published (Pel et al. 2007). This strain was derived from $A$. niger NRRL 3122 , a strain developed for glucoamylase A production by classical mutagenesis and screening methods (van Lanen and Smith 1968). This work initiated a number of new genome-based investigations (Sun et al. 2007; Andersen et al. 2008ab; Martens-Uzunova and Schaap 2008; Yuan et al. 2008ab) but did not reveal differences between citricacid-producing and enzyme-producing $A$. niger strains (Cullen 2007).

In this study, we present the nearly complete genome sequence of the citric-acid-producing A. niger wild-type strain ATCC 1015 and compare it to the genome sequence of the enzymeproducing strain CBS 513.88. The genetic diversity of these two $A$. niger strains was determined by applying systems biology tools as well as new bioinformatics methods to examine multi-level differences that distinguish the wild-type citric-acid-producing strain from the mutagenized glucoamylase A-producing strain.

\section{Results}

\section{General genome statistics}

The $34.85-\mathrm{Mb}$ genome sequence of $A$. niger ATCC 1015 was generated using a shotgun approach and then further improved to a high-quality assembly of 24 finished contigs separated by 15 gaps (including eight from centromeric regions). Genome statistics are summarized in Table 1, with details in Supplemental Text 1. The full sequence and annotations are available from the Joint Genome Institute (JGI) Genome Portal (http://genome.jgi-psf.org/Aspni5) and from NCBI (accession number ACJE00000000).

The genome sequence of $A$. niger CBS 513.88 (Pel et al. 2007) was improved using the ATCC 1015 sequence to close 186 contig gaps and modify the gene models associated with these gaps (Table 1; Supplemental Table 1). The updated A. niger CBS 513.88 genome sequence is accessible through EMBL (accession numbers AM269948AM270415).

We note a large difference (2882) in the number of called genes in the two strains (Table 1). A thorough analysis indicates an overprediction of genes in CBS 513.88 and an underprediction of genes in ATCC 1015, and 396/510 unique genes in CBS 513.88/
ATCC 1015 (Supplemental Text 2; Supplemental Fig. 1; for details, see Supplemental Tables 2-9). For further validation of the absence/presence of individual proteins, we have performed gDNA hybridizations, which can be consulted for reference (Supplemental Table 16).

Unique genes in both strains suggest horizontal gene transfer to be a cause for the amylase hyper-producer phenotype

For the genes unique to the amylase-producing strain CBS 513.88 (Supplemental Table 6), the most notable genes are two alphaamylases that are identical to the Aspergillus oryzae alpha-amylase, a possible cause for the amylase hyper-producer phenotype. We discuss this in detail below (Fig. 2). Furthermore, we find three possible polyketide synthases, which suggests a unique secondary metabolite profile for this strain.

Examining the genes found only in ATCC 1015 (Supplemental Table 6) does not point to any obvious cause for citric acid hyper-production, but four possible polyketide synthases and a putative NRPS are found to be unique for ATCC 1015, suggesting this strain has unique secondary metabolites as well. Multiple effects of this type are, indeed, seen for both strains in analyses below (Fig. 1; Supplemental Fig. 10; Table 2).

\section{Synteny mapping shows $0.5 \mathrm{Mb}$ of chromosomal rearrangements and a whole-arm inversion}

The genomes of the two strains are largely syntenic (Fig. 1). For example, the 1429 protein-encoding genes of CBS 513.88 supercontig An01 that have predicted counterparts in ATCC 1015 are, with one exception, all mapped to chromosome 2b. A similar example is seen for all but one of 1486 protein-encoding genes on supercontig An02. Both exceptions encode putative Tan1-like transposases. Notwithstanding, a number of significant differences in genome configuration exist (Fig. 1). More than $0.5 \mathrm{Mb}$ of additional genome sequence in ATCC 1015 resides in four large regions on chromosomes (Chr) II, III, and V (Fig. 1). The flanking sequences of three of these additional elements in ATCC 1015 are syntenic to continuous sequences in CBS 513.88 and are thus true differences in genome configuration (Supplemental Fig. 2; Supplemental Table 2; for details on ChrIII, see next section). The fourth region on the left arm of ChrV in ATCC 1015 could not be verified due to a contig gap for CBS 513.88. The contig gap in the right arm of ChrV in the genome sequence of ATCC 1015 is spanned by continuous sequence in CBS 513.88, containing 15 predicted genes. An overview of the genes found in the gaps unique to ATCC 1015 can be found in Supplemental Table 2 .

Other striking differences include a large inversion in ChrVIII and the inversion and translocation of a large fragment between the left arms of ChrIII and ChrVII (Supplemental Fig. 3). Both were confirmed with PCR spanning the breakpoints (data not shown).

Finally, the presence of telomere sequences in genome data confirms an inversion of the complete right arm of ChrVI.

Two extra alpha-amylase-encoding genes likely obtained through HGT

An unmatched region identified for the left arm of ChrIII (Fig. 1) spans $72.5 \mathrm{~kb}$ of 


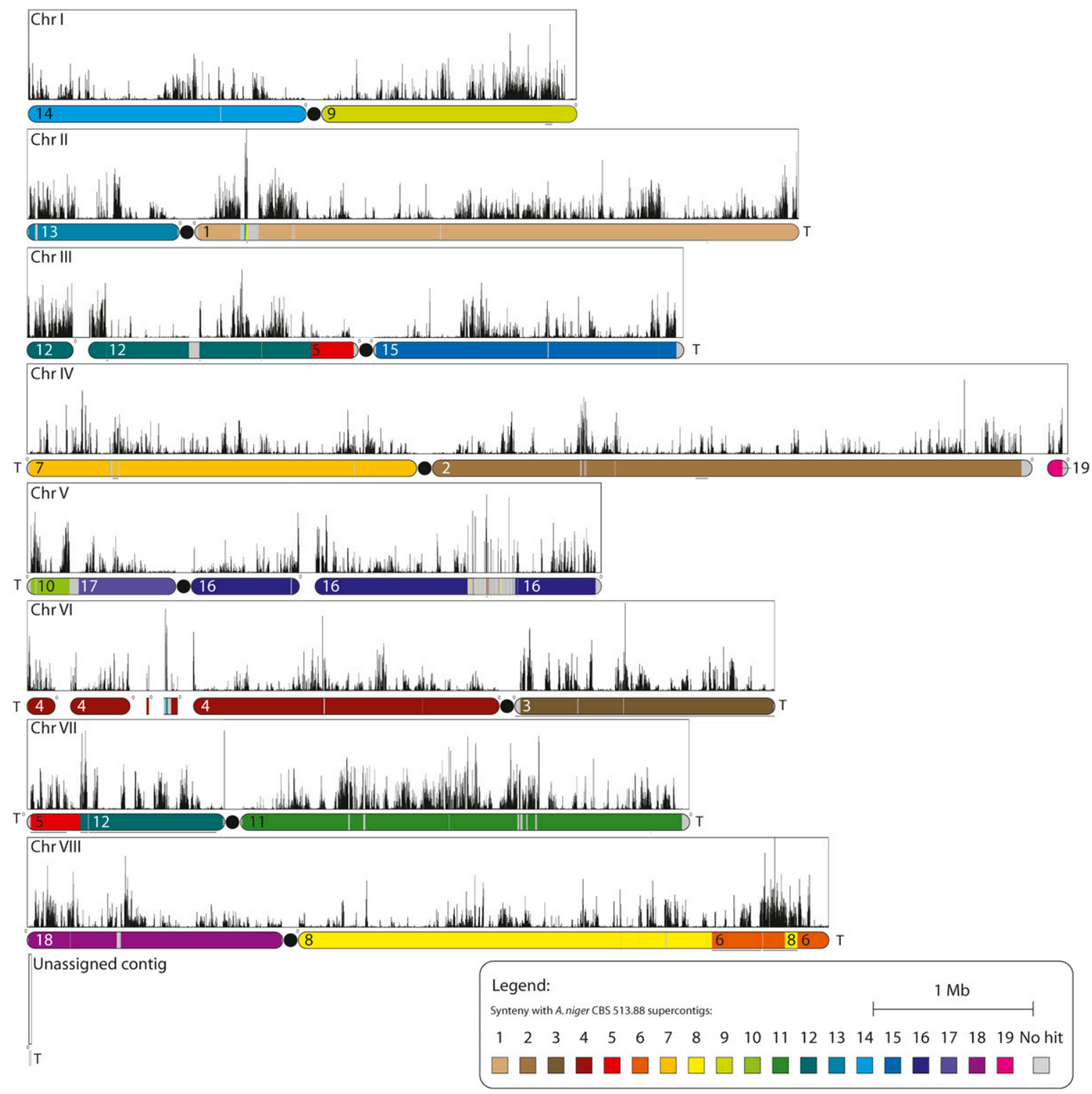

Figure 1. Synteny map of the contigs of $A$. niger ATCC 1015 to the supercontigs of $A$. niger CBS 513.88 . The coloring of the chromosomes shows syntenic regions in $A$. niger CBS 513.88. Arabic numerals show the number of the supercontig in A. niger CBS 513.88. Gray areas show regions not found in the CBS 513.88 genome sequence (Pel et al. 2007). (Filled black circles) Proposed locations of centromeric regions. Sequenced telomeres are marked with a T. Zeroes mark the first base of the contigs. A black line underneath a section of the chromosomes denotes inverted sequence. Black histograms show SNPs per kilobase (number of single nucleotide polymorphisms/kilobase) between the sequences of the two strains ( $y$-axis: 0-160 SNPs/kb). Gaps between contigs and centromeres are not to scale. The alignment demonstrates almost complete synteny between the two strains, with the exception of a cross-over event between the left arms of chromosomes III and VII. An overview of the genes found in the gaps unique to ATCC 1015 can be found in Supplemental Table 2.

unique sequence in ATCC 1015. Remarkably, for CBS 513.88, a unique $85.3-\mathrm{kb}$ sequence is found at this location (Fig. 2A). Gene annotation may be found in Supplemental Table 10. To confirm the actual absence of the region in the chromosome of ATCC 1015, we performed gDNA hybridizations, which did indeed support this finding (Supplemental Fig. 4).

Approximately $12 \mathrm{~kb}$ of this region shares $>99.8 \%$ sequence identity at DNA level with genomic DNA from A. oryzae RIB40 (Fig. 2B). The complete 85-kb fragment including the $12-\mathrm{kb}$ alphaamylase region also appears to be involved in a recent duplication recombination event to ChrVII, (Fig. 2C). Thus, the CBS 513.88 genome harbors two additional alpha-amylase-encoding genes that are orthologs to the alpha-amylase-encoding genes (AO090023000944, AO090120000196) of A. oryzae RIB40. These findings suggest that CBS 513.88 and the parental strain NRRL 3122 (data not shown) acquired these duplicate alpha-amylase genes (An12g06930, An05g02100) through horizontal gene transfer (HGT). The occurrence of HGT in Aspergilli would further be supported by the presence of alpha-amylase-encoding genes in other black Aspergilli that display $>99 \%$ nucleotide identity to those of $A$. oryzae RIB40 and the $A$. niger CBS 513.88 alpha-amylases (Korman et al. 1990; Shibuya et al. 1992). The origin of the 
Table 2. Exo-metabolomic profiling of 11 A. niger strains based on HPLC-DAD-FLD and HPLC-DAD-HRMS (this study)

\begin{tabular}{|c|c|c|c|c|c|c|c|c|c|c|c|c|}
\hline Secondary metabolites & Reference & $\begin{array}{l}\text { NRRL } \\
3122\end{array}$ & $\begin{array}{c}\text { CBS } \\
513.88^{a}\end{array}$ & $\begin{array}{c}\text { CBS } \\
126.49\end{array}$ & $\begin{array}{l}\text { ATCC } \\
1015^{a}\end{array}$ & $\begin{array}{l}\text { ATCC } \\
9029^{a}\end{array}$ & $\begin{array}{c}\text { CBS } \\
554.65\end{array}$ & $\begin{array}{c}\text { NRRL } \\
328\end{array}$ & $\begin{array}{c}\text { NRRL } \\
350\end{array}$ & $\begin{array}{c}\text { NRRL } \\
511\end{array}$ & $\begin{array}{l}\text { NRRL } \\
1278\end{array}$ & $\begin{array}{l}\text { NRRL } \\
2270\end{array}$ \\
\hline Aurasperone B & Tanaka et al. 1966 & - & - & • & • & • & • & • & • & $\bullet$ & • & • \\
\hline Fumonisin $B_{2}$ & Frisvad et al. 2007b & - & - & & - & - & - & - & - & - & - & - \\
\hline Funalenone & Inokoshi et al. 1999 & & & - & - & - & - & - & - & - & - & - \\
\hline Kotanin & Büchi et al. 1971 & & & - & - & - & - & - & - & - & - & - \\
\hline Nigragillin & Isogai et al. 1975 & - & - & & & & & & & & & \\
\hline Ochratoxin A & Abarca et al. 1994 & - & - & - & & & & & & & & \\
\hline Orlandin & Cutler et al. 1979 & & & - & • & $\bullet$ & • & • & • & • & • & • \\
\hline Other naphtho- $\gamma$-pyrones & & & & - & - & - & - & - & - & - & - & - \\
\hline Pyranonigrin $\mathrm{A}$ & Hiort et al. 2004 & - & - & - & - & - & - & - & - & - & - & - \\
\hline Tensidol B & Fukada et al. 2006 & - & - & - & - & - & - & - & - & - & - & - \\
\hline
\end{tabular}

The reference column relates to the elucidation of the compound structure.

${ }^{a}$ Genome-sequenced strains.

remaining part of the unmatched region remains unclear. No significant similarity was observed at the DNA level, and only a few of the encoded proteins show similarity with other proteins present in the NR protein database.

There is also evidence that this HGT may have occurred by the action of transposases. The 12-kb HGT region is flanked by 202-bp inverted, perfect, terminal repeats (ITR) (Fig. 2A,B). Furthermore, this HGT region harbors another gene, An12g07000, that is identical to the $A$. oryzae tnpA transposase gene. Interestingly, in the $A$. oryzae RIB40 genome, the same $12-\mathrm{kb}$ fragment has been duplicated twice and is present on multiple chromosomes, but only one perfect copy of the ITRs is retained (Fig. 2C).

\section{Transposon presence is strain-specific}

Transposon-like sequences were identified in both genomes and quantified (Supplemental Table 11). This comparison pinpoints a remarkable difference in the presence and amount of transposonrelated sequences in ATCC 1015 and CBS 513.88 both for class I and for class II transposons: Only 16 sequences were identified in ATCC 1015, but 55 were detected in CBS 513.88. Whereas the ATCC 1015 genome contains no class I superfamily copia and a single copy of class II superfamily Fot1/pogo, these sequences are much more abundant in CBS 513.88, where 15 class I copia, and 13 class II Fot1/pogo are found.

\section{SNP analysis reveals high mutation rates} and hypervariable regions

We found $8 \pm 16 \mathrm{SNPs} / \mathrm{kb}$ (average \pm standard deviation) and a maximum of $163 \mathrm{SNPs} / \mathrm{kb}$ single-nucleotide polymorphisms (SNPs) between A. niger strains ATCC 1015 and CBS 513.88 (Supplemental Table 12). This value is much higher than the maximum of $9 \mathrm{SNPs} / \mathrm{kb}$ found by Cuomo et al. (2007) in a SNP analysis of two Fusarium graminearum strains. A comparison of the A. niger ATCC 1015 genome sequence to that of $A$. niger ATCC 9029 revealed markedly less variation between the two $(2 \pm 5 \mathrm{SNPs} / \mathrm{kb})$ (Supplemental Fig. 5), indicating a large genomic variation in the A. niger group but little between ATCC 1015 and 9029. These polymorphisms are not uniformly distributed but cluster in hypervariable regions (Fig. 1). This is supported by a gDNA hybridization study, which confirms the presence of distinct hypervariable regions (Supplemental Fig. 4).
Gene comparisons reveal industrially relevant strain differences

To identify strain-defining systemic effects of the genome variation, results from the Imprint gene synteny analysis (see Supplemental Table 5; Methods) were used for additional genome-scale investigation.

GO term over-representation analysis was performed on gene groups with distinct common properties (for Group overview, see Supplemental Table 5; for details, see Supplemental Table 13). Most interesting is the observation that 37 proteins involved in transcriptional regulation are nonfunctional in CBS 513.88 due to frameshifts or stop codons. This suggests a less stringent regulation of CBS 513.88 relative to ATCC 1015. A comparative shake-flask study of the two strains also suggests mutations in regulatory elements as nitrogen source utilization is impaired in the CBS 513.88 strain (data not shown). While the nitrogen catabolism regulator AreA was originally thought to be mutated in CBS 513.88 (Pel et al. 2007), a resequencing of areA showed the ORFs to be identical.

To detect potential differences in the metabolism of the two strains, we compared all genes encoding proteins that display differences at the amino acid level between the two strains on the metabolic network of $A$. niger (Andersen et al. (2008a) and mapped them to metabolic pathways (Supplemental Fig. 6). Mutations were found in the pathways for biosynthesis of proline, aspartate, asparagine, tryptophan, and histidine, which may be relevant to protein production. Also, mutations were found in the plasma membrane-bound ATPase, in the enzymes of the GABA shunt, of the TCA cycle, and in components of all steps of the electron transport chain, which could be relevant for the production of citric acid.

\section{Phylogenetic analysis confirms high variability between genome sequences}

To place the comparison of $A$. niger ATCC 1015 and CBS 513.88 into the larger context of the Aspergillus section Nigri, variation in the two strains was analyzed by phylogenetic analysis of a part of the beta-tubulin sequence for a number of $A$. niger strains and other black Aspergilli (Fig. 3A). To further explore the genome variability across the $A$. niger species, we identified four $1-\mathrm{kb}$ regions from ChrII, ChrIV, ChrVI, and ChrVIII that were identical in the ATCC 1015 and ATCC 9029 strains but had $\sim 20$ SNPs/kb relative to the genome sequence of CBS 513.88. These regions were PCR-sequenced in seven A. niger strains including the CBS 513.88 progenitor, NRRL 


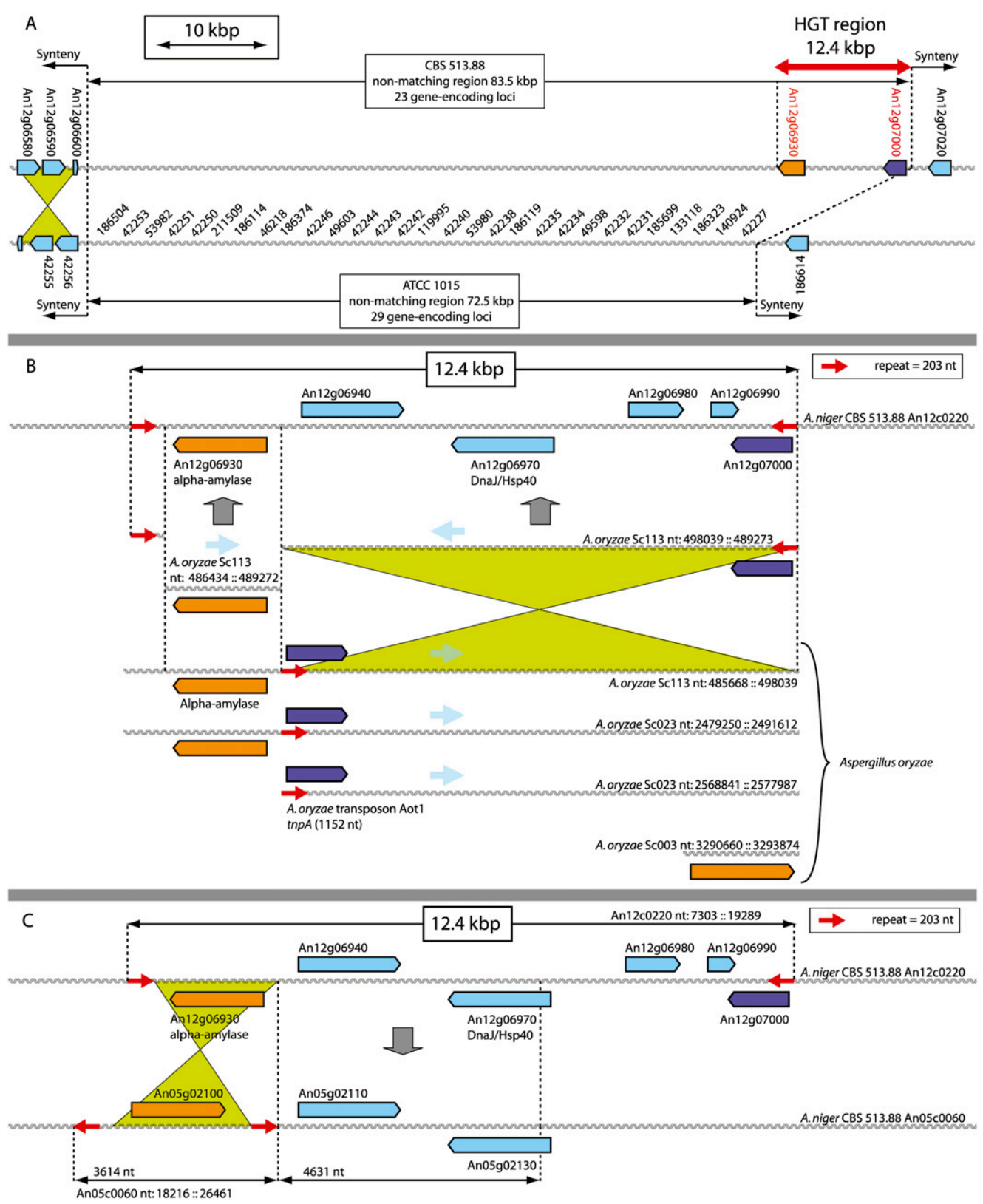

Figure 2. Horizontal gene transfer of alpha-amylase genes from A. oryzae to A. niger CBS 513.88. (A) Unmatched region identified for the left arm of chromosome III spanning $65 \mathrm{~kb}$ for ATCC 1015 encoding 30 predicted genes and $85 \mathrm{~kb}$ for CBS 513.88 encoding 24 predicted genes. The unmatched region is flanked on one side by a small local inversion of three predicted genes (in green). (B) The 12.4-kb HGT region is part of an identical 12.7-kb region present in $A$. oryzae RIB40 supercontigs SC113 and SC023. In A. niger CBS 513.88, the transferred region is enclosed by a 203-bp inverted repeat (red arrow). An12g07000 (blue) is a putative transposase and identical to the A. oryzae transposon Aot1 tnpA gene. Similarly, the A. niger CBS 513.88 alphaamylase encoding gene An12g06930 (orange) is identical to A. oryzae annotated genes AO090120000196 (SC113) and AO090023000944 (SC023). (C) Proposed duplication-recombination event between supercontig 12 and supercontig 05 of the 12-kb HGT region. Breakpoints are indicated with dotted lines. The fragment encoding alpha-amylase An05g02200 is identical to An12g06930 (orange). The breakpoints are flanked with additional copies of the 203-bp repeat region (red arrow). The region encoding genes An12g06940 to An12g06970 is identical to the region encoding An05g02210 to An05g02130. The downstream breakpoint occurred in the predicted gene coding region of An12g06970, thereby deleting the original start codon and upstream region.

3122, and the A. niger neotype strain, CBS 554.65 (Kozakiewicz et al. 1992) to form a phylogenetic tree with high variation (Fig. 3B). For previously sequenced strains, the resequencing results were identical to the previously determined genomic sequence, thereby excluding that the genomic variation is an artifact of lowfidelity sequencing.
All $A$. niger strains have an identical sequence for beta-tubulin and form a strongly supported terminal clade together with $A s$ pergillus awamori (Fig. 3A). The other taxonomically different species are phylogenetically distinct from this group, which is in accordance with the serial classification of Frisvad et al. (2007a). The latter clustering based on the selected regions (Fig. 3B) was able to 
A

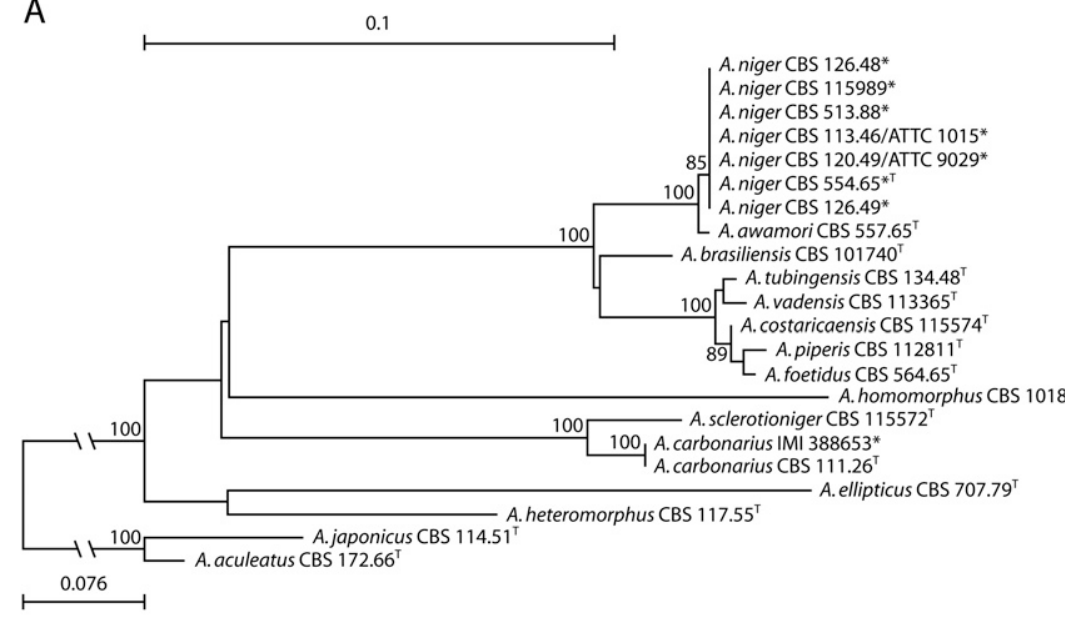

B

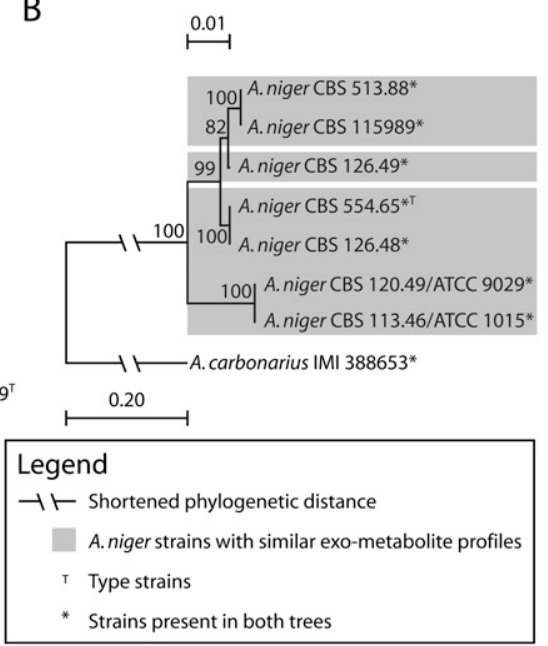

Figure 3. (A) Phylogenetic relationship of several black Aspergilli based on partial sequencing of beta-tubulin. The tree was rooted to Aspergillus aculeatus CBS 172.66. (B) Phylogenetic relationship of seven strains of $A$. niger based on sequencing of 1-kb variable regions from four chromosomes. The tree was rooted to the sequence obtained from Aspergillus carbonarius IMI 388653. Clades based on the exo-metabolomic groupings of Table 2 are shown. For both trees, bootstrap values above $80 \%$ of the 1000 performed reiterations are shown.

separate the $A$. niger strains into three groups. Strain CBS 513.88 and its progenitor NRRL 3122 were identical for the regions, indicating limited SNP introduction due to classical strain improvement, and thus confirms high variation in the A. niger group.

\section{Exo-metabolomic profiling describes three distinct groups of $A$. niger}

To further compare the two sequenced strains on a system-wide, but nongenomic level, to each other and to other members of the A. niger species group, exo-metabolomic profiles of the two strains were compared to nine other strains, including the CBS 513.88 progenitor strain, NRRL 3122; the widely used laboratory strain ATCC 9029; and the A. niger neotype, CBS 554.65 (Table 2). This gave three distinct clades, which follow the clustering of Figure $3 \mathrm{~B}$, but does not conform to the phylogenetic distances calculated. Strain CBS 513.88 and its progenitor strain had very similar secondary metabolite profiles. These two strains differed from the other strains analyzed. Strain ATCC 1015 had a profile similar to seven other strains, although there were some quantitative differences. Strain CBS 126.49 had a unique profile.

In the case of ochratoxin A, it is interesting that in ATCC 1015 and ATCC 9029, a remnant of the PKS gene (An15g07920) of the putative ochratoxin cluster in A. niger CBS 513.88 (Pel et al. 2007) was identified, which could be related to a $21-\mathrm{kb}$ deletion in both strains (Supplemental Fig. 7). We have noted that a putative NRPS is found in one of the unique chromosome regions found in ATCC 1015 (Fig. 1), which may account for some of the difference (Supplemental Table 2).

\section{Transcriptome analysis of $A$. niger ATCC 1015 and CBS 513.88 growing on glucose}

To evaluate the effect of the differences in genome sequence on the physiology of the two strains, batch cultivations in bioreactors and a comparative transcriptome analysis were performed. Strains ATCC 1015 and CBS 513.88 were grown under the same conditions in batch cultures in a glucose-based minimal medium. The
GlaA-producing strain CBS 513.88 produced $>1.2 \mathrm{~g} / \mathrm{L}$ GlaA more than ATCC 1015, while producing $\sim 1 \mathrm{~g} / \mathrm{L}$ biomass less. Other measured characteristics were similar for the two strains (Table 3 ). Statistical analysis showed 4784 significantly (adj. $p<0.05$ ) differentially expressed genes, with an almost equal number of genes up-regulated in either strain (2431 in CBS 513.88 vs. 2353 for ATCC 1015).

Examining the differential expression in the context of metabolic pathways (Supplemental Fig. 8), only the alternative oxidative pathway has uniformly higher expression in ATCC 1015, while a substantial subset of metabolism was up-regulated in CBS 513.88 , including glycolysis and the TCA cycle. As the specific growth rates of the strains are similar, we suggest that this extra activity of central metabolism provides precursors for the higher productivity of glucoamylase. We also find increased expression of genes involved in amino acid metabolism, especially the entire biosynthetic pathways of threonine, serine, and tryptophan.

Table 3. Statistics for batch cultivations of A. niger ATCC 1015 and A. niger CBS 513.88

\begin{tabular}{|c|c|c|}
\hline & ATCC 1015 & CBS 513.88 \\
\hline mRNA (h) & $24.5 \pm 1.2$ & $40.2 \pm 4.2$ \\
\hline Biomass (g/L) & $5.0 \pm 0.1$ & $4.0 \pm 0.5$ \\
\hline$\mu_{\max }\left(h^{-1}\right)$ & $0.17 \pm 0.01$ & $0.15 \pm 0.01$ \\
\hline Glucose (g/L) & $10.0 \pm 0.6$ & $9.5 \pm 0.4$ \\
\hline Glycerol (g/L) & $0.09 \pm 0.02$ & $0.27 \pm 0.03$ \\
\hline $\mathrm{Y}_{\mathrm{xs}}(\mathrm{Cmol} / \mathrm{Cmol})^{\mathrm{a}}$ & $0.67 \pm 0.03$ & $0.55 \pm 0.03$ \\
\hline GlaA $(g / L)^{b}$ & $0.24 \pm 0.08$ & $1.57 \pm 0.23$ \\
\hline Citric acid (q/L) & $0.10 \pm 0.12$ & $0.14 \pm 0.03$ \\
\hline
\end{tabular}

Fermentations were performed in biological triplicates for each strain. Values are presented as average \pm standard deviation. $\mu_{\max }$ and $Y_{x s}$ are general statistics for the fermentations, while the remaining values are specific for the time of sampling for transcription analysis (see mRNA row). GlaA is glucoamylase $A$.

${ }^{a}$ Biomass was converted to $\mathrm{Cmol}$ using $24.9 \mathrm{~g}$ of biomass/Cmol (Nielsen et al. 2003).

${ }^{\mathrm{b}}$ One unit of glucoamylase can be assumed to correspond to $25 \mu \mathrm{g}$ of protein (PESL protein assay; Boehringer Mannheim). 
Intriguingly, analysis of the amino acid composition of the glucoamylase A protein (Supplemental Fig. 9) revealed that GlaA is atypical in that it has a higher content of specifically tryptophan, threonine, and serine than $90 \%$ of the predicted genes of CBS 513.88. For all three amino acids, the content is almost twice as high as the average in the composition of total protein (Christias et al. 1975).

We initially thought that this was due to a frameshift mutation identified in the gene for the general amino acid-regulating transcription factor (cross-pathway control protein) CpcA (Supplemental Table 5), but resequencing of this gene showed this frameshift to be a sequencing error. The presence of two sense mutations was confirmed and is currently being investigated.

To further support that the increased production of GlaA is significant enough to affect amino acid biosynthesis, we used a genome-scale metabolic model of $A$. niger (Andersen et al. 2008a) to model the two strains under the growth conditions used (Table 3). The computed fluxes (Supplemental Table 14) show that for all three amino acids, the fluxes through the biosynthetic pathways must be at least twice as high in CBS 513.88 compared to ATCC 1015 to support the increased GlaA production, thus corresponding well with the transcriptome results.

For a broader analysis of trends revealed by the transcriptome profiles, a GO term over-representation analysis was conducted on the genes significantly up-regulated in either strain (Supplemental Table 15). The analysis confirmed that traits relevant for protein production-such as amino acid biosynthesis and tRNA aminoacylation-appear to be highly significant for CBS 513.88. For ATCC 1015, GO biological functions for electron transport (adj. $\left.p=2.7 \times 10^{-5}\right)$, carbohydrate transport (adj. $\left.p=6.8 \times 10^{-3}\right)$, and organic acid transport (adj. $p=0.035$ ) were significant.

An examination of expression of individual genes showed that glaA had significantly increased expression in CBS 513.88 (adj. $p=84 \times 10^{-6}$ ), but the fold change (3.2) was lower than the increase in enzyme activity (sixfold) (Table 3 ). Interestingly, all identified tRNA-aminoacyl synthases were found to be twofold to sixfold up-regulated in CBS 513.88.

\section{Mapping of gene expression to the genome identifies secondary metabolite cluster activities and underpins the whole-arm inversion in chromosome VI}

To examine differences in gene expression between the two strains relative to chromosome positions, the $\log _{2}$-ratios of the gene expression indices from the transcriptome analysis were mapped to the synteny diagrams of Figure 1 (Supplemental Fig. 10).

The analysis of this mapping identified a number of features. First, six regions not found in CBS 513.88 contain genes with uniformly higher expression in ATCC 1015, supporting the absence of these regions in CBS 513.88. Second, two active secondary metabolite clusters were identified on ChrVIII (contains a polyketide synthase [ID: 211885] that is unique for ATCC 1015) and ChrI (NRPS cluster, found in both strains [NRPS ID: 43555/ An09g00520], but appears only to be active in CBS 513.88). Third, the inversion of the entire right arm of ChrVI (Fig. 1) is further supported. The telomeric position effect, which defines decreased expression in the vicinity of telomeres, has been described for Saccharomyces cerevisiae (Gottschling et al. 1990). Thus, if an arm has been inverted, reduced expression should be found at opposite ends in ATCC 1015 and CBS 513.88. This is indeed reflected in the $\log _{2}$-ratio on the right arm of ChrVI (Supplemental Fig. 10).

\section{Discussion}

In this study, we provide and compare the genomes of two strains of $A$. niger. These two strains have different phenotypes: one, the predecessor to efficient enzyme-producing strains having undergone some level of mutagenesis and selection, and the other a wild-type parent strain of high citric-acid-producing strains. This makes the comparison interesting both in terms of genomic research and industrial applications. We have supported the conclusions of our comparison with further experiments, allowing us to propose new hypotheses and conclusions within three main areas: (1) genetic diversity of the $A$. niger group, (2) horizontal gene transfer in fungi, and (3) fungal biotechnology (discussed separately below).

The diversity of the two strains was explored through a multilevel comparison (DNA, chromosome, gene, and protein) between both genome architectures and was supported by multiple types of experimental work. Interestingly, we observe a remarkable similarity at the level of chromosome, gene order, and gene identity, but also notable diversity was detected and further explored, namely, distinct regions with high levels of SNPs, a $0.8-\mathrm{Mb}$ difference in genome size, several large insertion/deletions of up to $200 \mathrm{~kb}$, different transposon populations, a major translocation/ inversion, the inversion of an entire chromosomal arm, and a large set of unique genes in both species (see points 1-5 below):

1. About 400-500 unique genes were identified for each strain, most of which are evenly distributed over the chromosomes. This indicates strain evolution by a high frequency of loss and/or uptake of gene fragments. Interestingly, the opposite is seen in two strains of the pathogenic Aspergillus fumigatus, where $80 \%$ of the strain-specific genes (143 and 218, respectively) are found in a few, large isolate-specific genomic islands (Fedorova et al. 2008). Thus, this intra-species increased frequency of transfer/loss of genetic elements so far seems to be specific for the A. niger group. More genome sequences may prove it to be present in other Aspergilli as well.

2. The whole-arm inversion on ChrVI is a remarkable event. Over the characterized Aspergilli sequenced genomes, most described inversions were isolated as mutants, with a breakpoint in a gene, leading to a phenotype. Pel et al. (2007) reported high synteny between the centromeric parts of the arms of $A$. niger CBS 513.88 and Aspergillus nidulans FGSC A4. Even so, in this case, it is supported by the genome sequence, the presence of telomeric sequences, and a detectable telomeric positioning effect. From Figure 2 in Galagan et al. 2005, it is also clear that centromeric inversions must have occurred in the genealogy of the common ancestor of $A$. nidulans, A. oryzae, and A. fumigatus.

3. The large translocation/inversion event of ChrIII and ChrVII explains the discrepancies in chromosome size reported by Pel et al. (2007) between strain N400 (Verdoes et al. 1994) and calculated sizes of ChrIII and ChrVII for CBS 513.88. This fact and that the breakpoints are within two otherwise intact genes indicate that the event occurred after the branching of strains N400 and NRRL 3122, possibly in the mutagenesis of the predecessor of CBS 513.88.

4. The presence and functionality of transposons are qualitatively and quantitatively less complex in the genome of ATCC 1015 than in CBS 513.88 (Supplemental Table 11). Such a different distribution of transposons between strains has been observed before (Braumann et al. 2008) and was described to be inducible by mutagenesis and other stress-induced conditions (Strand and 
McDonald 1985). However, the number and scale of differences make a recent mutagenesis program unlikely to be the basis for the multiple HGT events. Furthermore, the detection of repeat sequences in a number of DNA regions was accompanied by strain-specific differences. Therefore, we suggest that the transposon populations have played a significant role in strain evolution.

5. Finally, the phylogenetic analysis (Fig. 3B) confirms the high genetic variation described for two strains to be general within the $A$. niger group and not the result of either CBS 513.88 or ATCC 1015 being atypical. This is again supported by the exometabolomic profiles of the 11 examined $A$. niger strains (Table 2). While the grouping of the exo-metabolites does not accurately reflect the cladograms in Figure 3, we see this as confirmation of the high genetic variation in the $A$. niger group, as the production of a given exo-metabolite may be changed by a single genomic event. Thus, we believe that the diversity of the two genome-sequenced strains is common for the $A$. niger group, which seems to have highly dynamic genomes.

The presence/absence of HGT in fungi has caused a lot of discussion (Galagan et al. 2005; Keeling and Palmer 2008; Khaldi and Wolfe 2008; Khaldi et al. 2008). In this study, we have shown HGT to be a most likely origin of two alpha-amylase genes in CBS 513.88 that might have been transferred to $A$. niger from another species, possibly A. oryzae. The HGT must have occurred before the separation of CBS 513.88 and ATCC 1015. The amylase genes are not found in the ATCC 1015 strain (also supported by gDNA hybridization), but they are in CBS 513.88 flanked by a transposon, which is found both in A. oryzae RIB40 and in a truncated form in ATCC 1015. With the evidence of HGT into Aspergillus clavatus from a Magnaporthe-related donor, presented by Khaldi et al. (2008), HGT is now identified in two separate cases with distantly related species and may thus be seen as a general phenomenon in filamentous fungi.

The initial reason for comparing the two strains has been to gain insight in the genetic basis for the two industrially relevant phenotypes. In citric-acid-producing ATCC 1015, we are intrigued to see higher expression of elements from the electron transport, carbohydrate transport, and organic acid transport. These factors are known to be involved in obtaining high citric acid yields. Higher expression levels even though citric acid production is not notably higher (see discussion below) suggests that these traits may have been contributing factors to the original selection of ATCC 1015 for citric acid production. For the GlaA-producing strain (CBS 513.88), we observe systemic changes: Mutations in regulatory genes (e.g., $c p c A$ ), higher expression of gla $A$ itself, and up-regulation of all identified tRNA-synthases may all contribute to a more efficient enzyme producer. We also present the hypothesis that increased production of the amino acids serine, threonine, and tryptophan may be required for efficient GlaA production, as these are over-represented in GlaA.

While we have identified multiple possible contributors to the efficient amylase production of CBS 513.88, we have only seen a few factors associated with citric acid production. We propose multiple reasons for this: (1) CBS 513.88 was selected for increased GlaA production, while ATCC 1015 is a wild-type strain with only modest citric acid production (compared to current yields). (2) The medium used for the transcriptome analysis is not optimized for citric acid production, as this would not give the dispersed growth necessary for representative sampling (Karaffa and Kubicek 2003). (3) Protein synthesis is a complex process, with more factors in- volved than in the production and secretion of a simple organic acid. Since more than 6000 genes differ at the amino acid level between the two strains, it would be unlikely not to find many differences involved in protein production. For this reason, we have put our emphasis on genes found in multiple types of analyses, effects in entire pathways, and traits (GO) that are found to be statistically over-represented, which allows for robust conclusions.

In conclusion, our results establish a firm comparative genomics foundation on which to build and test hypotheses regarding enzyme production, organic acid production, and diversity within a "species group."

\section{Methods}

\section{ATCC 1015 genome assembly}

The sequence reads were derived from four whole-genome shotgun (WGS) libraries: one with an insert size of $2-3 \mathrm{~kb}$, two with an insert size of $6-8 \mathrm{~kb}$, and one with an insert size of 35-40 kb. The reads were screened for vector using cross_match and then trimmed for vector sequence and quality (J Chapman, N Putnam, I Ho, and D Rokhsar, unpubl.). Reads shorter than 100 bases after trimming were excluded. The final data set included: 28,551 of $2-3-\mathrm{kb}$ reads, containing $21.5 \mathrm{Mb}$ of sequence; 160,479 of $6-8-\mathrm{kb}$ reads, containing $123 \mathrm{Mb}$ of sequence; and 38,651 of $35-40-\mathrm{kb}$ reads, containing $23.8 \mathrm{Mb}$ of sequence.

The data were assembled using release 2.7 of Jazz, a WGS assembler developed at the JGI (Aparicio et al. 2002; J Chapman, N Putnam, I Ho, and D Rokhsar, unpubl.). The genome size and sequence depth were initially estimated to be $36 \mathrm{Mb}$ and 8.0, respectively. After removal of short $(<1 \mathrm{~kb})$ and redundant scaffolds ( $<5 \mathrm{~kb}$ with $80 \%$ or more of the length matching a scaffold $>5 \mathrm{~kb}$ ), the assembly included $43.7 \mathrm{Mb}$ of scaffold sequence with $8.2 \mathrm{Mb}$ (18.9\%) of gaps in 350 scaffolds, with half of the scaffold sequence contained in the eight largest scaffolds of $1.81 \mathrm{Mb}$ or longer. The sequence depth derived from the assembly was $7.88 \pm 0.05$. To estimate the completeness of the assembly, a set of 50,001 ESTs was BLAT-aligned to the unassembled trimmed reads, as well as the assembly itself. Forty-three thousand three hundred and twentythree ESTs $(86.6 \%)$ were $>80 \%$ covered by the unassembled data; $43,978(88.0 \%)$ were $>50 \%$ covered; and $44,206(88.4 \%)$ were $>20 \%$ covered. By way of comparison, 48,798 ESTs (97.6\%) showed hits to the assembly. Orientation of the chromosome arms was based on eight available telomere sequences, the supercontig orientation proposed by Pel et al. (2007), and research on linkage groups in A. niger (Bos et al. 1989; Debets et al. 1989, 1990a,b; Swart et al. 1992; Verdoes et al. 1994).

\section{ATCC 1015 genome finishing}

To perform genome improvement on A. niger ATCC 1015, initial read layouts from the whole-genome shotgun assembly were converted into the phred/phrap/consed pipeline (Gordon et al. 1998). Following manual inspection of the assembled sequences, finishing was performed by resequencing plasmid subclones and by walking on plasmid subclones or fosmids using custom primers. All finishing reactions were performed with 4:1 BigDye to dGTP BigDye terminator chemistry (Applied Biosystems). Repeats in the sequence were resolved by transposon-hopping 8-kb plasmid clones. Fosmid clones were shotgun sequenced and finished to fill large gaps, resolve large repeats, or to resolve chromosome duplications and extend into chromosome telomere regions.

The resulting 24 finished scaffolds were orientated where possible into chromosome structures using comparisons to Pel et al. (2007) and telomere positions. The improved genome consists of

\section{Genome Research}


$34,853,277$ bp with an estimated error rate of less than 1 error in $100,000 \mathrm{bp}$.

\section{ATCC 1015 automatic annotation}

Gene models in the genome of $A$. niger were predicted using Fgenesh (Salamov and Solovyev 2000), Fgenesh+ (Salamov and Solovyev 2000), and Genewise (Birney and Durbin 2000) integrated into the JGI annotation pipeline. Fgenesh was trained on a set of more than 2000 putative full-length transcripts derived from clustered $A$. niger ESTs and reliable homology-based gene models to show $81 \%$ sensitivity and $81 \%$ specificity of predictions on a test set. Homologybased gene predictors were seeded with BLASTX alignments of proteins from the NCBI nonredundant set of proteins. Thirty-one thousand five hundred and seventy-eight $A$. niger ESTs were sequenced using Sanger technology and were either directly mapped to genomic sequence when the ESTs included putative full-length (FL) genes or used to extend predicted gene models into FL genes by adding $5^{\prime}$ and/or $3^{\prime}$ UTRs. In addition, 386,515 ESTs with an average length of $104 \mathrm{nt}$ were sequenced with 454 Life Sciences (Roche) GS20 sequencers and used in validation of predicted gene models. Since multiple gene models were generated for each locus, a single representative model was chosen based on homology and EST support and used for further analysis.

All predicted gene models were functionally annotated by sequence similarity to annotated genes from the NCBI nonredundant set and other specialized databases (such as KEGG) (Kanehisa et al. 2002, 2004) using BLAST and hardware accelerated double-affine Smith-Waterman alignments (http://www.timelogic. com). Functional and structural domains were predicted in protein sequences using the InterPro software (Zdobnov and Apweiler 2001). All genes were also annotated according to Gene Ontology (Ashburner et al. 2000; Harris et al. 2004), eukaryotic orthologous groups (KOGs) (Koonin et al. 2004), and KEGG metabolic pathways (Kanehisa et al. 2004).

\section{ATCC 1015 sequence availability}

A. niger assemblies, annotations, and analyzes are available through the interactive JGI Genome Portal at http://genome.jgipsf.org/Aspni5/Aspni51.home.html. Genome assemblies together with predicted gene models and annotations were also deposited at NCBI under the project accession number ACJE00000000.

\section{Strains}

The following A. niger strains were used for experiments (deposition numbers in different collections are given as well): CBS $513.88=$ FGSC A1513 = IBT 29270, ATCC $1015=$ IBT $28639=$ NCTC $3858 \mathrm{a}=$ NRRL $1278=$ NRRL $350=$ NRRL $511=$ NRRL $328=$ Thom $167=$ CBS $113.46=$ ATCC $10582=$ IMI $031821=$ LSBH Ac $4=$ Thom 3528.7, NRRL 3 = IBT $28539=$ MUCL $30480=$ DSM $2466=$ CECT $2088=$ VTT D $-85240=$ NRRL $566=$ WB3 $=$ ATCC $9029=\mathrm{N} 400=$ CBS $120.49=$ IMI 041876, NRRL $326=$ IBT $27876=$ WB $326=$ CBS $554.65=$ ATCC $16888=$ IHEM $3415=$ IMI $050566=$ Thom $2766=$ JCM 10254 = IFO 33023 (ex tannin-gallic acid fermentation; A. niger neotype) (Kozakiewicz et al. 1992) NRRL $328=$ IBT $27878=$ NRRL $350=$ IBT $27877=$ CBS 113.46, NRRL $337=$ CBS $126.48=$ ATCC $10254=$ DSM $734=$ IFO 6428 = IMI $015954=$ WB 337, NRRL $363=$ IBT $3617=$ IBT $5764=$ CBS $126.49=$ ATCC $10698=$ IFO 6648, NRRL $511=$ IBT 27875, NRRL $1278=$ IBT 27872, NRRL $2270=$ IBT $26391=$ ATCC $11414=$ VTT D-77050 = IMI $075353=$ A60 = S.M. martin A-1-233 = Wisconsin 72-4, derived from ATCC 1015, and NRRL $3122=$ IBT $23538=$ ATCC $22343=$ CBS 115989 (this strain is a wild-type progenitor of CBS 513.88). Strain histories for ATCC 1015, ATCC 9029, and NRRL 3122 are reviewed by Baker (2006).

\section{Exo-metabolite profiling}

A. niger strains were inoculated on Czapek yeast autolysate (CYA), yeast extract sucrose (YES) agar, and CYA with $5 \% \mathrm{NaCl}$ agar (CYAS agar). For medium composition, see Frisvad and Samson (2004). All strains were three-point inoculated on these media and incubated at $25^{\circ} \mathrm{C}$ in darkness for a week, after which five plugs $(6 \mathrm{~mm}$ diameter) along a diameter of a fungal colony were cut out and extracted (Smedsgaard 1997). The extracts were analyzed by HPLCDAD fluorescence (Frisvad and Thrane 1987; Smedsgaard 1997) and by HPLC-HR-MS (Nielsen and Smedsgaard 2003; Frisvad et al. 2007b). The secondary metabolites were identified by comparison with authentic standards (fumonisin $\mathrm{B}_{2}$, ochratoxin A, nigragillin, kotanin, and orlandin) and by UV spectra and high-resolution mass spectra using electrospray ionization.

\section{CBS 513.88 gap closure}

The near-complete ATCC 1015 genome sequence was used to verify contig order and orientation and to estimate gap sequence length between contigs in CBS 513.88. Gap-flanking PCR primers (20-mers) giving rise to PCR products with a minimal overlap of $100 \mathrm{bp}$ were automatically designed with primer-3 (Rozen and Skaletsky 2000) using custom scripts. PCR products of expected size were purified using a QIAquick PCR Purification Kit (QIAGEN) and sequenced by Baseclear. The updated sequence for $A$. niger CBS 513.88 is available from EMBL (http://www.ebi.ac.uk/embl/) under accession nos. AM269948-AM270415.

\section{Sequencing of variable regions}

Regions were amplified using standard PCR techniques with the four following primer pairs (the name describes chromosome number and direction): (1) ChrO2-Fwd: 5'-GGACACTGCTTGATG TGATG-3', ChrO2-Rev: 5'-GAGAGACGTACGAAAGGTTG-3'; (2) Chr04-Fwd: 5'-CGATCTGCGACCAGGA-3', Chr04-Rev: 5'-CATAA CGGATTCGTCGCTG-3'; (3) Chr06-Fwd: 5'-CTTGAAGGCGTTGA GGTC-3', Chr06-Rev: 5'-GCGAGTATGTGGCTAACATC-3'; (4) Chr08Fwd: 5'-GGTATGTCACATTCCRTCCA-3', Chr08-Rev: 5'-GCTTGC AGTGAGCAAGGA-3'. The sequences on ChrII, ChrVI, and ChrVIII overlap with predicted genes. The PCR products were purified using a QIAquick PCR Purification Kit (QIAGEN) and sequenced by Agencourt Bioscience Corporation (GenBank accession number GU296708-GU296739).

\section{Sequencing of beta-tubulin}

Amplification of part of the beta-tubulin gene was performed using the primers Bt2a (GGTAACCAAATCGGTGCTGCTTTC) and Bt2b (ACCCTCAGTGTAGTGACCCTTGGC) (Glass and Donaldson 1995). Both strands of the PCR fragments were sequenced with the ABI Prism Big DyeTM Terminator v.3.0 Ready Reaction Cycle sequencing kit. Samples were analyzed on an ABI PRISM 3700 Genetic Analyzer, and contigs were assembled using the forward and reverse sequences with the program SeqMan from the LaserGene package (GenBank accession numbers GU296686-GU296707).

\section{Calculation of phylogenetic tree}

Sequences were aligned using ClustalX and trimmed to the first common base at both ends before making the final alignment. For the tree of Figure 3B, four trimmed sequences were joined for each strain before making the final alignment. Tree calculations were performed using TreeCon (van de Peer and de Wachter 1994). Distances were estimated using the Jukes and Cantor algorithm taking insertions and deletions into account. Topology was 
inferred using neighbor joining with bootstrap values based on 1000 reiterations.

\section{Comparison of protein-encoding loci}

The loci were compared using megablast of CBS 513.88 cDNA sequences Version 2008 with standard setting followed by parsing of the output for local pairwise sumscore of HSPs.

\section{Fermentation procedure}

\section{Growth media}

The $A$. niger batch cultivation medium was $20 \mathrm{~g} / \mathrm{L}$ glucose monohydrate, $7.3 \mathrm{~g} / \mathrm{L}\left(\mathrm{NH}_{4}\right)_{2} \mathrm{SO}_{4}, 1.5 \mathrm{~g} / \mathrm{L} \mathrm{KH}_{2} \mathrm{PO}_{4}, 1.0 \mathrm{~g} / \mathrm{L} \mathrm{MgSO}{ }_{4} \cdot 7 \mathrm{H}_{2} \mathrm{O}$, $1 \mathrm{~g} / \mathrm{L} \mathrm{NaCl}, 0.1 \mathrm{~g} / \mathrm{L} \mathrm{CaCl} 2 \cdot 2 \mathrm{H}_{2} \mathrm{O}, 0.05 \mathrm{~mL} / \mathrm{L}$ antifoam 204 (Sigma), and $1 \mathrm{~mL} / \mathrm{L}$ trace element solution. The trace element solution composition was $7.2 \mathrm{~g} / \mathrm{L} \mathrm{ZnSO}_{4} \cdot 7 \mathrm{H}_{2} \mathrm{O}, 0.3 \mathrm{~g} / \mathrm{L} \mathrm{NiCl}_{2} \cdot 6 \mathrm{H}_{2} \mathrm{O}, 6.9 \mathrm{~g} / \mathrm{L}$ $\mathrm{FeSO}_{4} \cdot 7 \mathrm{H}_{2} \mathrm{O}, 3.5 \mathrm{~g} / \mathrm{L} \mathrm{MnCl}_{2} \cdot 4 \mathrm{H}_{2} \mathrm{O}$, and $1.3 \mathrm{~g} / \mathrm{L} \mathrm{CuSO}_{4} \cdot 5 \mathrm{H}_{2} \mathrm{O}$. The A. niger complex medium was $2 \mathrm{~g} / \mathrm{L}$ yeast extract, $3 \mathrm{~g} / \mathrm{L}$ tryptone, $10 \mathrm{~g} / \mathrm{L}$ glucose monohydrate, $20 \mathrm{~g} / \mathrm{L}$ agar, $0.52 \mathrm{~g} / \mathrm{L} \mathrm{KCl}, 0.52 \mathrm{~g} / \mathrm{L}$ $\mathrm{MgSO}_{4} \cdot 7 \mathrm{H}_{2} \mathrm{O}, 1.52 \mathrm{~g} / \mathrm{L} \mathrm{KH}_{2} \mathrm{PO}_{4}$, and $1 \mathrm{~mL} / \mathrm{L}$ of trace elements solution. The trace elements solution was $0.4 \mathrm{~g} / \mathrm{L} \mathrm{CuSO}_{4} \cdot 5 \mathrm{H}_{2} \mathrm{O}, 0.04$ $\mathrm{g} / \mathrm{L} \mathrm{Na}_{2} \mathrm{~B}_{4} \mathrm{O}_{7} \cdot 10 \mathrm{H}_{2} \mathrm{O}, 0.8 \mathrm{~g} / \mathrm{L} \mathrm{FeSO}_{4} \cdot 7 \mathrm{H}_{2} \mathrm{O}, 0.8 \mathrm{~g} / \mathrm{L} \mathrm{MnSO}_{4} \cdot \mathrm{H}_{2} \mathrm{O}, 0.8$ $\mathrm{g} / \mathrm{L} \mathrm{Na}_{2} \mathrm{MoO}_{4} \cdot 2 \mathrm{H}_{2} \mathrm{O}$, and $8 \mathrm{~g} / \mathrm{L} \mathrm{ZnSO}{ }_{4} \cdot 7 \mathrm{H}_{2} \mathrm{O}$.

\section{Spore propagation}

The bioreactors were inoculated with spores of $A$. niger CBS 513.88 or ATCC 1015 strains previously propagated on complex media plates and incubated for $8 \mathrm{~d}$ at $30^{\circ} \mathrm{C}$. The same stock of spores was used to inoculate all the plates. Spores were harvested by adding $10 \mathrm{~mL}$ of Tween $800.01 \%$, centrifuged at $4000 \mathrm{rpm}$ for $10 \mathrm{~min}$, and washed three times with a suitable amount of $0.9 \% \mathrm{NaCl}$. The fermentors were inoculated with a spore suspension to obtain a final concentration of $5.7 \times 10^{9}$ spores $/ \mathrm{L}$.

\section{Batch cultivations}

A. niger batch cultivations were carried out in 5-L reactors with a working volume of $4.5 \mathrm{~L}$. The bioreactors were equipped with two Rushton four-blade disc turbines, and $\mathrm{pH}$ and temperature control. Inlet air was controlled with a mass flowmeter. The concentrations of oxygen and carbon dioxide in the exhaust gas were monitored with a gas analyzer (1311 Fast response Triple gas, Innova combined with multiplexer controller for Gas Analysis MUX100, B. Braun Biotech International). The temperature was maintained at $30^{\circ} \mathrm{C}$, and the $\mathrm{pH}$ was controlled by automatic addition of $2 \mathrm{M}$ $\mathrm{NaOH}$. The $\mathrm{pH}$ was initially set to 3.0 to prevent spore aggregation; when spores started to germinate, the $\mathrm{pH}$ was gradually increased to 4.5 . Similarly, the stirring speed was initially set to $200 \mathrm{rpm}$ and the aeration rate to $0.05 \mathrm{vvm}$ (volume of gas per volume of liquid per minute) to prevent loss of hydrophobic spores from the medium to the head space of the reactor. After germination, these parameters were progressively increased to $600 \mathrm{rpm}$ and $0.89 \mathrm{vvm}$ and kept steady throughout all the rest of the fermentation.

\section{Sampling}

For quantification of cell mass and extracellular metabolites, the fermentation broth was withdrawn from the reactor, filtered, and washed. The filter cakes were used for cell weight determination. The filtrate was filtered once more and frozen at $-20^{\circ} \mathrm{C}$ for later HPLC analysis. For gene expression analysis, mycelium was harvested in the exponential phase of growth at half the maximum biomass density by filtration through sterile Miracloth (Calbiochem) and washed with a suitable amount of $0.9 \% \mathrm{NaCl}$ solution. The mycelium was quickly dried by squeezing and subsequently frozen in liquid nitrogen. Samples were stored at $-80^{\circ} \mathrm{C}$ until used for RNA extraction.

\section{Cell mass determination}

Cell dry weight was determined using paper filters (Whatmann cat. no. 1001070). The filters were pre-dried in an oven for $24 \mathrm{~h}$ at $100^{\circ} \mathrm{C}$, cooled down in a desiccator for $2 \mathrm{~h}$, and subsequently weighed. A known volume of cell culture was filtered, and the residue was washed with $0.9 \% \mathrm{NaCl}$ and dried on the filter for $24 \mathrm{~h}$ in an oven at $100^{\circ} \mathrm{C}$. The filter was weighed again, and the cell mass concentration was calculated. Dry biomass was converted to $\mathrm{Cmol}$ using $24.9 \mathrm{~g}$ biomass/Cmol (Nielsen et al. 2003).

\section{Quantification of sugars and extracellular metabolites}

The concentrations of sugar and organic acids in the filtrates were determined using HPLC on an Aminex HPX-87H ion-exclusion column (Bio-Rad). The column was eluted at $60^{\circ} \mathrm{C}$ with $5 \mathrm{mM}$ $\mathrm{H}_{2} \mathrm{SO}_{4}$ at a flow rate of $0.6 \mathrm{~mL} / \mathrm{min}$. Metabolites were detected with a refractive index detector and an UV detector.

\section{Determination of glucoamylase activity}

The activity of glucoamylase in culture filtrates was quantified spectrophotometrically using $p$-nitrophenyl $\beta$-maltoside as the substrate for glucoamylase (McCleary et al. 1991). Ninety microliters of $200 \mathrm{mM}$ sodium acetate $(\mathrm{pH} 4.4)$ was added to $10 \mu \mathrm{L}$ of enzyme solution (standards or fermentation broth), mixed, and shaken for $30 \mathrm{sec}$ in a microtiter plate, then incubated for $5 \mathrm{~min}$ at $40^{\circ} \mathrm{C}$. Ten microliters of this mixture was mixed with $10 \mu \mathrm{L}$ of substrate containing $p$-nitrophenyl $\beta$-maltoside plus thermostable $\beta$-glucosidase (Megazyme). This preparation was shaken for $30 \mathrm{sec}$ and incubated for $10 \mathrm{~min}$ at $40^{\circ} \mathrm{C}$. The reaction was stopped by the addition of $150 \mu \mathrm{L}$ of trizma base solution $2 \%$. The sample preparation was shaken again for $30 \mathrm{sec}$ and measured at $405 \mathrm{~nm}$ in a spectrophotometer. The absorbance measurement was related to enzyme units per milliliter according to the calibration curve. One unit of enzyme is the amount of enzyme that liberates $1 \mu \mathrm{mol}$ of glucose per minute at $\mathrm{pH} 4.8$ and $60^{\circ} \mathrm{C}$. One unit can be assumed to correspond to $25 \mu \mathrm{g}$ of protein (PESL protein assay; Boehringer Mannheim).

\section{Transcriptome analysis}

\section{Extraction of total RNA, preparation of biotin-labeled cRNA, and microarray processing}

Total RNA was isolated from 70-90 mg of frozen mycelium. Twenty micrograms of fragmented biotin-labeled cRNA was prepared from $\sim 1 \mu \mathrm{g}$ of total RNA. Fifteen micrograms of fragmented cRNA was hybridized to the 3AspergDTU GeneChip, washed, stained, and scanned. The scanned probe array images (.DAT files) were converted into .CEL files using the Affymetrix GeneChip Operating Software. All steps were performed as in Andersen et al. (2008b).

\section{Analysis of transcription data}

Statistical analysis of the Affymetrix CEL-files was performed as described in Andersen et al. (2008b). Note that this method uses the medianpolish algorithm (Irizarry et al. 2003), which should make calculations of gene expression indexes relatively robust to differences in the genome sequences. A cutoff value of adjusted $p<0.05$ was set to assess statistical significance. Normalized and raw data values are deposited with GEO as series GSE10983.

\section{Genome Research}




\section{GO-term enrichment analysis}

A. niger ATCC 1015 ORF lists were examined for GO-term enrichment using R-2.5.1 (http://www.R-project.org) with BioConductor (Gentleman et al. 2004) and the topGO-package v. 1.2.1 using the elim algorithm to remove local dependencies between GO terms (Alexa et al. 2006). GO-term assignments were based on automatic annotation of the A. niger ATCC 1015 gene models. Where nothing else is noted, $p<0.05$ is used as the cutoff for significance.

\section{Genomic DNA hybridization analysis}

Genomic DNA was prepared with the GNOME kit (Bio101). This DNA was fragmented in a Hydroshear (Genemachines) as per the manufacturer's protocol for 20 cycles with speed code 4 , to yield DNA fragments of $\sim 1.5 \mathrm{~kb}$. This fragmented DNA was further digested to a size of 50-200 nt by partial DNase I digestion (Invitrogen) and labeled with biotin using biotin ddUTP and Terminal deoxynucleotide transferase of the "Bioarray Terminal Labelling kit" (Enzo). Thirteen micrograms of fragmented and labeled DNA was hybridized to the dsmM_ANIGERa_coll511030F GeneChip, washed, stained, and scanned. The images were converted into data files, probe set values, and signal log ratios using the Affymetrix GCOS software. The obtained data set is given in Supplemental Table 16. The dsmM_ANIGERa_coll511030F library and platform information is deposited at GEO under number GPL6758.

\section{Genome-scale modeling}

Flux calculation was performed as described in Andersen et al. (2008a) using the $A$. niger iMA871 model. Specifically, fluxes were calculated for ATCC 1015 and CBS 513.88 using the growth conditions of the experiments described in Table 3 and using the concentrations of glucose, glycerol, glucoamylase, and citric acid from Table 3. The calculated fluxes may be found in Supplemental Table 14.

\section{Synteny analysis}

The finished version of the $A$. niger ATCC 1015 genome sequence was divided into fragments of $1 \mathrm{~kb}$ and compared to the nucleotide sequence of $A$. niger CBS 513.88 using BLASTN (McGinnis and Madden 2004). A cutoff value of $1 \times 10^{-75}$ was used. The BLAST results were parsed using a custom-made Perl script, giving for each $1-\mathrm{kb}$ fragment the location of the hit and the number of SNPs, insertions, and deletions. The same analysis was performed for a comparison of the A. niger ATCC 1015 and A. niger ATCC 9029 genome sequences.

\section{Transcription mapping}

The nucleotide sequence of the gene models of the $A$. niger ATCC 1015 genome sequence v1.0 was mapped to the 24 contigs of the finished sequence by BLASTN. A cutoff value of $1 \times 10^{-100}$ was used. An adapted version of the Imprint algorithm (see below) was used to find the coordinates of each gene. $\log _{2}$-ratios of the average expression ratios in each of the two strains were mapped to the coordinate of the first base of the gene finding a hit in the target genome.

\section{Imprint algorithm}

The object of the algorithm is, for every coding sequence of $A$. niger ATCC 1015, to present the corresponding genomic sequence from
A. niger CBS 513.88 (the Imprint), so that an unbiased comparison of two sets of gene callers can be conducted.

The CDSs of $A$. niger ATCC 1015 were compared to the nucleotide sequence of $A$. niger CBS 513.88 using BLASTN (McGinnis and Madden 2004). The BLASTN output was parsed to extract-for each gene-the alignment to the A. niger CBS 513.88 sequence. This provided for each gene, the part of the CDS having a hit in the CBS 513.88 sequence, and the corresponding sequence from CBS 513.88 sequence (the Imprint). The CDS and the Imprint were compared to produce a comprehensive list of insertions, deletions, silent mutations, sense mutations, frameshift mutations, and nonsense mutations for each CDS pair. Detail on the analysis and manual curation of the results can be found in Supplemental Text 3. The final summary is found in Supplemental Table 5. All genes were assigned to one of the categories of Supplemental Table 5. Genes were only assigned to categories E-F if none of the requirements of categories G-L were fulfilled. Manual and automatic annotation was added for 9400 genes, including all genes with $>0.5 \%$ difference in amino acid sequence.

\section{List of Affiliations}

${ }^{1}$ Center for Microbial Biotechnology, Department of Systems Biology, Technical University of Denmark, DK-2800 Kongens Lyngby, Denmark; ${ }^{2}$ Section Fungal Genomics, Laboratory of Microbiology, Wageningen University, Dreijenplein 10, $6703 \mathrm{HB}$ Wageningen, The Netherlands; ${ }^{3}$ DSM Biotechnology Center, 2600 MA Delft, The Netherlands; ${ }^{4}$ Fungal Biotechnology Team, Pacific Northwest National Laboratory, Richland, Washington 99352, USA; ${ }^{5}$ Biomax Informatics AG, D-82152 Martinsried, Germany; ${ }^{6}$ Novozymes Inc., Davis, California 95616, USA; ${ }^{7}$ Molecular Microbiology and Genetics, Georg-August University, D-37077 Goettingen, Germany; ${ }^{8}$ Departamento de Genetica, Universidad de Sevilla, E-41080 Sevilla, Spain; ${ }^{9}$ DSM Nutritional Products, 2600 MA Delft, The Netherlands; ${ }^{10}$ Novozymes A/S, Hallas Alle 1, BD3.44, DK-4400 Kalundborg, Denmark; ${ }^{11}$ CBS Fungal Biodiversity Centre, Uppsalalaan 8, 3584 CT Utrecht, The Netherlands; ${ }^{12}$ Centre for Structural and Functional Genomics, Concordia University, Montreal, QC, Canada H4B 1R6; ${ }^{13} \mathrm{Chr}$. Hansen A/S, Bøge Allé 10-12, DK-2970 Hørsholm, Denmark; ${ }^{14}$ U.S. Department of Energy Joint Genome Institute, Walnut Creek, California 94598, USA; ${ }^{15}$ Joint Genome Institute, Stanford Human Genome Center, Palo Alto, California 94304, USA; ${ }^{16}$ Research Area of Gene Technology and Applied Biochemistry, Institute of Chemical Engineering, Vienna University of Technology, Getreidemarkt 9-1665, A-1060 Vienna, Austria; ${ }^{17}$ Los Alamos National Laboratory, Los Alamos, New Mexico 87545, USA; ${ }^{18}$ Department of Biology, University of New Mexico, Albuquerque, New Mexico 87131, USA.

\section{Acknowledgments}

This study was partially funded by the Danish Research Agency for Technology and Production (to M.R.A., S.L.M., J.B.N., and M.L.N.) and the National Council of Research Conacyt-Mexico (to M.P.S.). Genome sequencing was performed under the auspices of the U.S. Department of Energy's Office of Science, Biological and Environmental Research Program, and by the University of California, Lawrence Berkeley National Laboratory under contract No. DEAC02-05CH11231, Lawrence Livermore National Laboratory under Contract No. DE-AC52-07NA27344, and Los Alamos National Laboratory under contract No. DE-AC02-06NA25396. Preparation of genomic DNA and some analysis of the genome were supported by the DOE Office of the Biomass Program. 


\section{References}

Abarca ML, Bragulat MR, Castella G, Cabanes FJ. 1994. Ochratoxin A production by strains of Aspergillus niger var. niger. Appl Environ Microbiol 60: $2650-2652$.

Alexa A, Rahnenführer J, Lengauer T. 2006. Improved scoring of functional groups from gene expression data by decorrelating $\mathrm{GO}$ graph structure. Bioinformatics 22: 1600-1607.

Andersen MR, Nielsen M, Nielsen J. 2008a. Metabolic model integration of the bibliome, genome, metabolome and reactome of Aspergillus niger. Mol Syst Biol 4: 178. doi: 10.1038/msb.2008.12.

Andersen MR, Vongsangnak W, Panagiotou G, Salazar M, Lehmann L, Nielsen J. 2008b. A tri-species Aspergillus micro array: Comparative transcriptomics of three Aspergillus species. Proc Natl Acad Sci 105: 43874392.

Aparicio S, Chapman J, Stupka E, Putnam N, Chia JM, Dehal P, Christoffels A, Rash S, Hoon S, Smit A, et al. 2002. Whole-genome shotgun assembly and analysis of the genome of Fugu rubripes. Science 297: 1301-1310.

Ashburner M, Ball CA, Blake JA, Botstein D, Butler H, Cherry JM, Davis AP, Dolinski K, Dwight SS, Eppig JT, et al. 2000. Gene ontology: tool for the unification of biology. The Gene Ontology Consortium. Nat Genet 25: 25-29.

Baker SE. 2006. Aspergillus niger genomics: Past, present and into the future. Med Mycol (Suppl 1) 44: S17-S21.

Birney E, Durbin R. 2000. Using GeneWise in the Drosophila annotation experiment. Genome Res 10: 547-548.

Bos CJ, Debets AJ, Kobus G, Slakhorst SM, Swart K. 1989. Adenine and pyrimidine genes of Aspergillus niger and evidence for a seventh linkage group. Curr Genet 16: 307-310.

Braumann I, van den Berg M, Kempken F. 2008. Strain-specific retrotransposon-mediated recombination in commercially used Aspergillus niger strain. Mol Genet Genomics 280: 319-325.

Büchi G, Klaubert D, Shank R, Weinreb S, Wogan GN. 1971. Structure and synthesis of kotanin and desmethylkotanin, metabolites of Aspergillus glaucus. J Org Chem 36: 1143-1147.

Christias C, Couvaraki C, Georgopoulos SG, Vomvoyanni V. 1975. Protein content and amino acid composition of certain fungi evaluated for microbial protein production. Appl Microbiol 29: 250-254.

Cullen D. 2007. The genome of an industrial workhorse. Nat Biotechnol 25: 189-190.

Cuomo CA, Güldener U, Xu JR, Trail F, Turgeon BG, Di Pietro A, Walton JD, Ma LJ, Baker SE, Rep M, et al. 2007. The Fusarium graminearum genome reveals a link between localized polymorphism and pathogen specialization. Science 317: 1400-1402.

Cutler HG, Crumley FG, Cox RH, Hernandez O, Cole RJ, Dorner JW. 1979. Orlandin: a nontoxic fungal metabolite with plant growth inhibiting properties. J Agric Food Chem 27: 592-595.

Debets A, Swart K, Bos C. 1989. Mitotic mapping in linkage group V of Aspergillus niger based on selection of auxotrophic recombinants by Novozym enrichment. Can J Microbiol 35: 982-988.

Debets A, Holub E, Swart K, van den Broek H, Bos C. 1990a. An electrophoretic karyotype of Aspergillus niger. Mol Gen Genet 224: 264 268.

Debets A, Swart K, Bos C. 1990b. Genetic analysis of Aspergillus niger: Isolation of chlorate resistance mutants, their use in mitotic mapping and evidence for an eighth linkage group. Mol Gen Genet 221: 453458.

Fedorova ND, Khaldi N, Joardar VS, Maiti R, Amedeo P, Anderson MJ, Crabtree J, Silva JC, Badger JH, Albarraq A, et al. 2008. Genomic islands in the pathogenic filamentous fungus Aspergillus fumigatus. PLoS Genet 4: e1000046. doi: 10.1371/journal.pgen.1000046.

Frisvad JC, Samson R. 2004. Polyphasic taxonomy of Penicillium subgenus Penicillium. A guide to identification of the food and air-borne terverticillate Penicillia and their mycotoxins. Stud Mycol 49: 1-52.

Frisvad JC, Thrane U. 1987. Standardized high performance liquid chromatography of 182 mycotoxins and other fungal metabolites based on alkylphenone indices and UV VIS spectra (diode array detection). J Chromatogr 404: 195-214.

Frisvad JC, Larsen TO, de Vries R, Meijer M, Houbraken J, Cabañes FJ, Ehrlich K, Samson RA. 2007a. Secondary metabolite profiling, growth profiles and other tools for species recognition and important Aspergillus mycotoxins. Stud Mycol 59: 31-37.

Frisvad JC, Smedsgaard J, Samson R, Larsen T, Thrane U. 2007b. Fumonisin B2 production by Aspergillus niger. J Agric Food Chem 55: 9727-9732.

Fukuda T, Hasegawa Y, Hagimori K, Yamaguchi Y, Masuma R, Tomoda $\mathrm{H}$, Omura S. 2006. Tensidols, new potentiators of antifungal miconazole activity, produced by Aspergillus niger FKI-2342. J Antibiot (Tokyo) 59: 480-485.

Galagan JE, Calvo SE, Cuomo C, Ma LJ, Wortman JR, Batzoglou S, Lee SI, Baştürkmen M, Spevak CC, Clutterbuck J, et al. 2005. Sequencing of
Aspergillus nidulans and comparative analysis with $A$. fumigatus and $A$. oryzae. Nature 438: 1105-1115.

Gentleman RC, Carey VJ, Bates DM, Bolstad B, Dettling M, Dudoit S, Ellis B, Gautier L, Ge Y, Gentry J, et al. 2004. Bioconductor: Open software development for computational biology and bioinformatics. Genome Biol 5: R80. doi: 10.1186/gb-2004-5-10-r80.

Glass NL, Donaldson GC. 1995. Development of primer sets designed for use with the PCR to amplify conserved genes from filamentous ascomycetes. Appl Environ Microbiol 61: 1323-1330.

Gordon D, Abajian C, Green P. 1998. Consed: A graphical tool for sequence finishing. Genome Res 8: 195-202.

Gottschling D, Aparicio O, Billington B, Zakian V. 1990. Position effect at $S$. cerevisiae telomeres: Reversible repression of Pol II transcription. Cell 63: 751-762.

Harris MA, Clark J, Ireland A, Lomax J, Ashburner M, Foulger R, Eilbeck K, Lewis S, Marshall B, Mungall C, et al. 2004. The Gene Ontology (GO) database and informatics resource. Nucleic Acids Res 1: D258-D261.

Hiort J, Maksimenka K, Reichert M, Perović-Ottstadt S, Lin WH, Wray V, Steube K, Schaumann K, Weber H, Proksch P, et al 2004. New natural products from the sponge-derived fungus Aspergillus niger. J Nat Prod 67: 1532-1543.

Inokoshi J, Shiomi K, Masuma R, Tanaka H, Yamada H, Omura S. 1999. Funalenone, a novel collagenase inhibitor produced by Aspergillus niger. J Antibiot (Tokyo) 52: 1095-1100.

Irizarry RA, Hobbs B, Collin F, Beazer-Barclay YD, Antonellis KJ, Scherf U, Speed TP. 2003. Exploration, normalization, and summaries of high density oligonucleotide array probe level data. Biostatistics 4: 249264.

Isogai A, Horii T, Suzuki A, Murakoshi S, Ikeda K, Sato S, Tamura S. 1975. Isolation and identification of nigragillin as an insecticidal metabolite produced by Aspergillus niger. Agric Biol Chem 39: 739-740.

Kanehisa M, Guto S, Kawashima S, Nakaya A. 2002. The KEGG databases at GenomeNet. Nucleic Acids Res 30: 42-46.

Kanehisa M, Goto S, Kawashima S, Okuno Y, Hattori M. 2004. The KEGG resource for deciphering the genome. Nucleic Acids Res 32: D277-D280.

Karaffa L, Kubicek CP. 2003. Aspergillus niger citric acid accumulation: do we understand this well working black box? Appl Microbiol Biotechnol 61: 189-196.

Keeling PJ, Palmer JD. 2008. Horizontal gene transfer in eukaryotic evolution. Nat Rev Genet 9: 605-617.

Khaldi N, Wolfe KH. 2008. Elusive origins of the extra genes in Aspergillus oryzae. PLoS ONE 3: e3036. doi: 10.1371/journal.pone.0003036.

Khaldi N, Collemare J, Lebrun MH, Wolfe KH. 2008. Evidence for horizontal transfer of a secondary metabolite gene cluster between fungi. Genome Biol 9: R18. doi: 10.1186/gb-2008-9-1-r18.

Koonin EV, Fedorova ND, Jackson JD, Jacobs AR, Krylov DM, Makarova KS, Mazumder R, Mekhedov SL, Nikolskaya AN, Rao BS, et al. 2004. A comprehensive evolutionary classification of proteins encoded in complete eukaryotic genomes. Genome Biol 5: R7. doi: 10.1186/gb-20045-2-r7.

Korman DR, Bayliss FT, Barnett CC, Carmona CL, Kodama KH, Royer TJ, Thompson SA, Ward M, Wilson LJ, Berka RM. 1990. Cloning, characterization, and expression of two alpha-amylase genes from Aspergillus niger var. awamori. Curr Genet 17: 203-212.

Kozakiewicz Z, Frisvad JC, Hawksworth DL, Pitt JI, Samson RA, Stolk AC. 1992. Proposals for nomina specifica conservanda and rijicienda in Aspergillus and Penicillium (Fungi). Taxon 41: 109-113.

Lubertozzi D, Keasling JD. 2008. Developing Aspergillus as a host for heterologous expression. Biotechnol Adv 27: 53-75.

Martens-Uzunova ES, Schaap PJ. 2008. An evolutionary conserved Dgalacturonic acid metabolic pathway operates across filamentous fungi capable of pectin degradation. Fungal Genet Biol 45: 1449-1457.

McCleary BV, Bouhet F, Driguez H. 1991. Measurement of amyloglucosidase using p-nitrophenyl b-maltoside as substrate. Biotechnol Tech 5: 255258.

McGinnis S, Madden T. 2004. BLAST: at the core of a powerful and diverse set of sequence analysis tools. Nucleic Acids Res 32: W20-W25.

Nielsen KF, Smedsgaard J. 2003. Fungal metabolite screening: database of 474 mycotoxins and fungal metabolites for dereplication by standardized liquid chromatography-UV-mass spectrometry methodology. J Chromatogr A 1002: 111-136.

Nielsen J, Villadsen J, Liden G. 2003. Bioreaction engineering principles, 2nd ed. Kluwer Academic/Plenum, New York.

Pel HJ, de Winde JH, Archer DB, Dyer PS, Hofmann G, Schaap PJ, Turner G de Vries RP, Albang R, Albermann K, et al. 2007. Genome sequencing and analysis of the versatile cell factory Aspergillus niger CBS 513.88. Nat Biotechnol 25: 221-231.

Rozen S, Skaletsky H. 2000. Primer3 on the WWW for general users and for biologist programmers. In Bioinformatics methods and protocols: Methods in molecular biology (ed. S Krawetz, S Misener), pp. 365-386. Humana, Totowa, NJ.

\section{Genome Research}


Salamov AA, Solovyev VV. 2000. Ab initio gene finding in Drosophila genomic DNA. Genome Res 10: 516-522.

Schuster E, Dunn-Coleman N, Frisvad JC, van Dijck PWM. 2002. On the safety of Aspergillus niger—a review. Appl Microbiol Biotechnol 59: 426-435.

Shibuya I, Tamura G, Ishikawa T, Hara S. 1992. Cloning the alpha-amylase cDNA of Aspergillus shirousamii and its expression in Saccharomyces cerevisiae. Biosci Biotechnol Biochem 56: 174-179.

Smedsgaard J. 1997. Micro-scale extraction procedure for standardised screening of fungal metabolite production in cultures. J Chromatogr A 760: $264-270$.

Strand DJ, McDonald JF. 1985. Copia is transcriptionally responsive to environmental stress. Nucleic Acids Res 13: 4401-4410.

Sun J, Lu X, Rinas U, Zeng A. 2007. Metabolic peculiarities of Aspergillus niger disclosed by comparative metabolic genomics. Genome Biol 8: R182. doi: 10.1186/gb-2007-8-9-r182.

Swart K, Debets AJ, Kobus G, Bos CJ. 1992. Arginine and proline genes of Aspergillus niger. Antonie van Leeuwenhoek 61: 259-264.

Tanaka H, Wang PL, Yamada O, Tamura L. 1966. Yellow pigments of Aspergillus niger and Asp. awamori. Part. I. Isolation of aurasperone A and related pigments. Agric Biol Chem 30: 107-113.

van de Peer Y, de Wachter R. 1994. TREECON for Windows: a software package for the construction and drawing of evolutionary trees for the Microsoft Windows environment. Comput Appl Biosci 10: 569-570.

van Dijck PWM. 2008. The importance of Aspergilli and regulatory aspects of Aspergillus nomenclature. In Aspergillus in the genomic era (ed. J Varga,
RA Samso), pp. 249-257. Wageningen Academic, Wageningen, The Netherlands.

van Dijck PWM, Selten GCM, Hempenius RA. 2003. On the safety of a new generation of DSM Aspergillus niger production strains. Regul Toxicol Pharmacol 38: 27-35.

van Lanen JM, Smith MB. 1968. Process of producing glucamylase and an alcohol product. US patent 3,418,211. Hiram Walker \& Sons, Inc., Peoria, IL.

Verdoes JC, Calil MR, Punt PJ, Debets F, Swart K, Stouthamer AH, van den Hondel CA. 1994. The complete karyotype of Aspergillus niger: The use of introduced electrophoretic mobility variation of chromosomes for gene assignment studies. Mol Gen Genet 244: 75-80.

Yuan X, Roubos J, van den Hondel C, Ram A. 2008a. Identification of InuR, a new $\mathrm{Zn}$ (II)2Cys6 transcriptional activator involved in the regulation of inulinolytic genes in Aspergillus niger. Mol Genet Genomics 279: 11-26.

Yuan XL, van der Kaaij RM, van den Hondel CA, Punt PJ, van der Maarel MJ, Dijkhuizen L, Ram AF. 2008b. Aspergillus niger genome-wide analysis reveals a large number of novel $\alpha$-glucan acting enzymes with unexpected expression profiles. Mol Genet Genomics 279: 545-561.

Zdobnov EM, Apweiler R. 2001. InterProScan-an integration platform for the signature-recognition methods in InterPro. Bioinformatics 17: 847-848.

Received July 8, 2010; accepted in revised form March 9, 2011. 


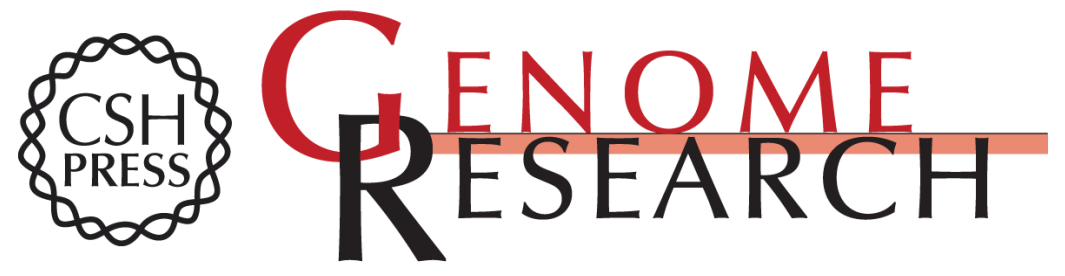

\section{Comparative genomics of citric-acid-producing Aspergillus niger ATCC 1015 versus enzyme-producing CBS 513.88}

Mikael R. Andersen, Margarita P. Salazar, Peter J. Schaap, et al.

Genome Res. 2011 21: 885-897 originally published online May 4, 2011

Access the most recent version at doi:10.1101/gr.112169.110

Supplemental Material

References This article cites 63 articles, 9 of which can be accessed free at: http://genome.cshlp.org/content/21/6/885.full.html\#ref-list-1

Open Access Freely available online through the Genome Research Open Access option.

License Freely available online through the Genome Research Open Access option.

Email Alerting
Service
top right corner of the article or click here.

\section{Affordable, Accurate Sequencing.}

